\title{
Effect of PGC-1 $\alpha$ on Proliferation, Migration, and Transdifferentiation of Rat Vascular Smooth Muscle Cells Induced by High Glucose
}

\author{
Xiaoqiang Qi, Yujing Zhang, Jing Li, Dongxia Hou, and Yang Xiang \\ Jiangsu Diabetes Center, State Key Laboratory of Pharmaceutical Biotechnology, School of Life Sciences, Nanjing University, \\ 22 Hankou Road, Nanjing 210093, China \\ Correspondence should be addressed to Yang Xiang, xiangy@nju.edu.cn
}

Received 15 April 2011; Revised 4 November 2011; Accepted 8 November 2011

Academic Editor: Kazim Husain

Copyright ( 2012 Xiaoqiang Qi et al. This is an open access article distributed under the Creative Commons Attribution License, which permits unrestricted use, distribution, and reproduction in any medium, provided the original work is properly cited.

\begin{abstract}
We assessed the role of PGC- $1 \alpha$ (PPAR $\gamma$ coactivator- 1 alpha) in glucose-induced proliferation, migration, and inflammatory gene expression of vascular smooth muscle cells (VSMCs). We carried out phagocytosis studies to assess the role of PGC-1 $\alpha$ in transdifferentiation of VSMCs by flow cytometry. We found that high glucose stimulated proliferation, migration and inflammatory gene expression of VSMCs, but overexpression of PGC- $1 \alpha$ attenuated the effects of glucose. In addition, overexpression of PGC- $1 \alpha$ decreased mRNA and protein level of VSMCs-related genes, and induced macrophage-related gene expression, as well as phagocytosis of VSMCs. Therefore, PGC- $1 \alpha$ inhibited glucose-induced proliferation, migration and inflammatory gene expression of VSMCs, which are key features in the pathology of atherosclerosis. More importantly, PGC-1 $\alpha$ transdifferentiated VSMCs to a macrophage-like state. Such transdifferentiation possibly increased the portion of VSMCs-derived foam cells in the plaque and favored plaque stability.
\end{abstract}

\section{Introduction}

Activation of vascular smooth muscle cells (VSMCs) including proliferation, migration, and inflammatory gene expression plays an important role in the development of atherosclerosis. In early atherosclerosis, VSMCs may contribute to the development of the atheroma through the production of preinflammatory mediators such as monocyte chemoattractant protein-1 (MCP-1) [1]. VSMC-derived foam cells have been demonstrated in vitro [2] and in vivo atherosclerotic plaques [3]. These foam cells assume a macrophage-like state [4].

Hyperglycemia has been implicated as a major contributor to several diabetes complications by inducing key factors including oxidant stress and inflammatory gene expression [5]. Furthermore, these factors may also lead to abnormal proliferation, migration and inflammatory gene expression of VSMCs, which are key features in the pathology of atherosclerosis. Recent studies have demonstrated that treatment of cultured VSMCs in vitro with diabetogenic agents such as high glucose can increase the production of various proinflammatory cytokines and chemokines, which are all associated with vascular inflammation [6].

PPAR $\gamma$ coactivator- 1 alpha (PGC- $1 \alpha$ ) is originally identified as a transcriptional coactivator of PPAR $\gamma$ [7]. PGC$1 \alpha$ can coactivate many nuclear receptors such as liver $\mathrm{X}$ receptor [8], and nonnuclear receptors such as Sry-related HMG box-9 [9]. As a metabolic regulator, PGC- $1 \alpha$ functions in adaptive thermogenesis in brown fat [7], gluconeogenesis in liver [10], and insulin secretion in islets [11]. Our group has demonstrated that PGC- $1 \alpha$ is an important negative regulator for VSMC proliferation and migration under pathophysiological conditions, such as oleic acid stimulation [12]. Additionally, PGC- $1 \alpha$ participates in the differentiation procedure including adipocyte differentiation [7] and chondrogenesis [9].

In the present study, we assessed the role of PGC- $1 \alpha$ in glucose-induced proliferation, migration, and inflammatory gene expression of VSMCs. We also carried out phagocytosis studies to assess the role of PGC- $1 \alpha$ in transdifferentiation of 
TABLE 1: Primer sequences for qRT-PCR, all sequences are from $5^{\prime}$ to $3^{\prime}$.

\begin{tabular}{lll}
\hline Genes & Forward primer & Reverse primer \\
\hline$\beta$-actin & AGGGAAATCGTGCGTGAC & CGCTCATTGCCGATAGTG \\
Myosin heavy chain & TCCGTGGGTGCAAATAAGG & CCGCTCCCAACCATCAACT \\
SM22 $\alpha$ & GAGGACTGTAATGGCTTTGG & GCCTTCCCTTTCTAACTGATG \\
Calponin H1 & GCACCAATAAGTTTGCCAGTC & GAGCGTGTCACAGTGTTCCAT \\
$\alpha$-actin & TCCTGACCCTGAAGTATCCG & ATCTCCAGAGTCCAGCACAA \\
CD68 & CTGACCTTGCTGGTACTGCT & GGTCGTAGGGCTTGCTGT \\
Mac-2 & CCTACGATATGCCCTTGCC & CCCAGTTATTGTCCTGCTTC \\
ABCA-1 & CCTGCTGAAATACCGACAA & TGAGGGACGATTCCACAT \\
MCP-1 & GCCTG TTGTTCACAGTTGC & TTCTGGACCCATTCCTTATT \\
IL-6 & GAGTTCCGTTTCTACCTG & CTTAGCCACTCCTTCTGT \\
\hline
\end{tabular}

VSMCs. We found that PGC- $1 \alpha$ inhibited glucose-induced VSMCs proliferation, migration, and inflammatory gene expression and furthermore resulted in phenotypic changes of VSMCs to a macrophage-like state.

\section{Materials and Methods}

2.1. Materials. Carboxylate-modified microspheres (F8821) with red fluorescent were purchased from Molecular Probes (Eugene, OR). RNeasy kit (cat. no.74104) and RNase-free DNase I (cat. no. 79254) were from QIAGEN. SYBR green PCR master mix (Part no.: 4309155) was from Applied Biosystems.

2.2. Cell Culture. Rat aortic VSMCs were isolated from the thoracic aortas of 3- to 4-week-old male SpragueDawley rats as described previously [13]. Isolated VSMCs were cultured in DMEM with $25 \mathrm{mmol} / \mathrm{L}$ or $5.5 \mathrm{mmol} / \mathrm{L} \mathrm{D-}$ glucose (Gibco-Invitrogen, Carlsbad, USA), supplemented with 10\% FCS (GBICO BRL, Rockville, MD), penicillin $(100 \mathrm{U} / \mathrm{mL})$, and streptomycin $(100 \mu \mathrm{g} / \mathrm{mL})$ at $37^{\circ} \mathrm{C}$ in a humidified atmosphere of $95 \%$ air and $5 \% \mathrm{CO}_{2}$. Cells after the 4 th to 8 th passages were used in experiments.

2.3. Adenovirus Infection. Recombinant adenoviruses expressing PGC- $1 \alpha$-GFP (Green Fluorescence Protein) fusion protein and GFP alone were provided by Dr. Dan Kelly (Washington University, Saint Louis, MO, USA). Purified virus stocks were prepared through $\mathrm{CsCl}$ density gradient centrifugation [14]. Cells were grown to subconfluence, deprived of serum for 24 hours, and followed by infection with adenovirus at multiplicities of infection (moi) of 50 for 48 hours. The infection efficiency was determined by fluorescence intensity of GFP.

2.4. RNA Analysis. Total RNA of VSMCs was isolated using RNeasy kit and RNase-free DNase I. RNA was reverse transcribed into cDNA with oligo (dT) 18 primers and AMV reverse transcriptase at $42^{\circ} \mathrm{C}$ for 1 hour in standard buffer (Table 1).

Quantitative PCR was performed with the ABI Prism 7000 sequence detection system (ABI, Foster City, CA).
SYBR green PCR master mix was used. The reactions were amplified for $30 \mathrm{~s}$ at $95^{\circ} \mathrm{C}$ and $1 \mathrm{~min}$ at $60^{\circ} \mathrm{C}$ for 40 cycles. The thermal denaturation protocol was run at the end of the PCR to determine the number of products that were present in the reaction. All reactions were run in triplicate and included no template and no reverse transcription controls for each gene. The relative amount of each mRNA to $\beta$-actin RNA was described using the equation $2-\Delta \mathrm{CT}$ where $\Delta \mathrm{CT}=$ (CTmRNA - CT $\beta$-actin) [15]. Relative gene expression was multiplied by $10^{4}$ in order to simplify the presentation of the data. The primers used in this study were listed in Table 1.

2.5. Western Blotting Analysis. To obtain total proteins, VSMCs were lysed in a buffer containing $10 \mathrm{mmol} / \mathrm{L}$ HEPES (pH 7.9), $1.5 \mathrm{mmol} / \mathrm{L} \mathrm{MgCl}_{2}, 10 \mathrm{mmol} / \mathrm{L} \mathrm{KCl}$, and $0.5 \%$ NP-40, and cell lysates were centrifuged at $13000 \mathrm{~g}$ for $5 \mathrm{~min}$. Supernatants were collected as cytosolic extracts for Western blot. Total proteins were applied to SDS-PAGE gel electrophoresis for proteins detection. The used primary antibodies included anti-pgc- $1 \alpha$ (sc-13067) and anti-CD68 (sc-9139) from Santa Cruz Biotechnologies, anti- $\beta$-actin (\#4967) from Cell Signaling, and anti- $\alpha$-actin (product no. A2547) from Sigma. After incubation with primary antibodies for $2 \mathrm{~h}$ and washing, membranes were incubated with corresponding horseradish-peroxidase (HRP-) conjugated secondary antibody and detected with the ECL Plus Kit (Amersham).

2.6. Migration Assays. Migration assays were performed by the modified Boyden chamber [16]. VSMCs were seeded in 6-well plates $\left(1.5 \times 10^{5}\right.$ cells/well $)$ and grew to subconfluence. After $24 \mathrm{~h}$ serum deprivation, VSMCs were treated with adenovirus infection for $48 \mathrm{~h}$. Boyden chamber cell migration assay was performed using transwell chambers with fibronectin- (Sigma)-coated $8 \mu \mathrm{m}$ poresize polycarbonate membranes (BD Biosciences). VSMCs treated were then suspended in low-glucose $(5.5 \mathrm{mmol} / \mathrm{L})$ DMEM- $0.5 \%$ FBS to a concentration of $4 \times 10^{5}$ cells $/ \mathrm{mL}$. Low glucose $(5.5 \mathrm{mmol} / \mathrm{L})$ or high glucose $(25 \mathrm{mmol} / \mathrm{L})$ DMEM $(0.6 \mathrm{~mL})$ supplemented with $10 \%$ FCS were added to the lower compartment. A $0.1 \mathrm{~mL}$ cell suspension (final concentration, $4 \times 10^{4}$ cells/well; diameter, $6.5 \mu \mathrm{m}$ ) was added to the upper compartment, and cells were then incubated at $37^{\circ} \mathrm{C}(95 \%$ 

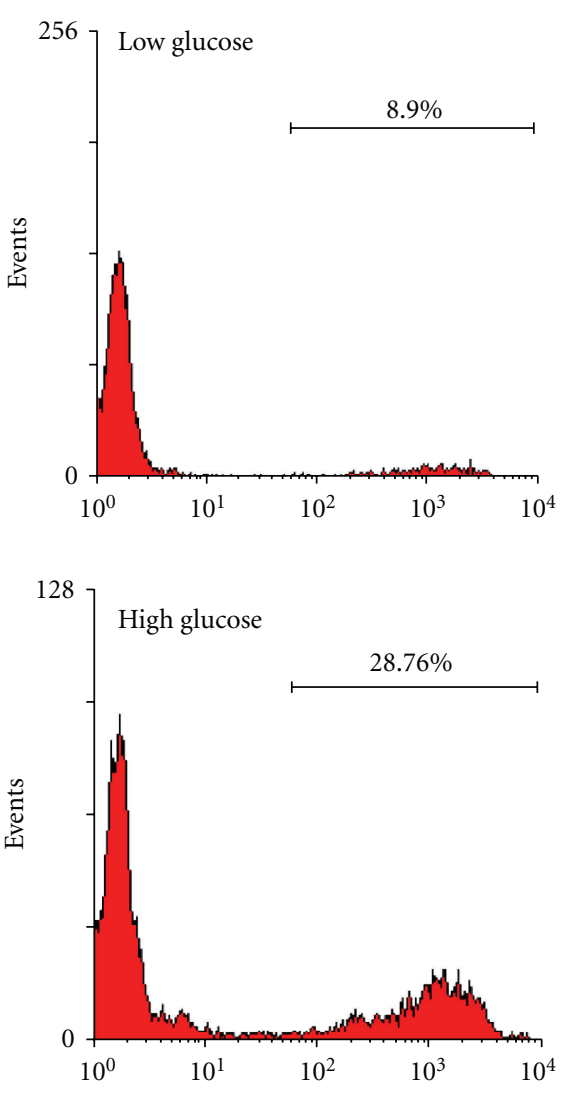

(a)
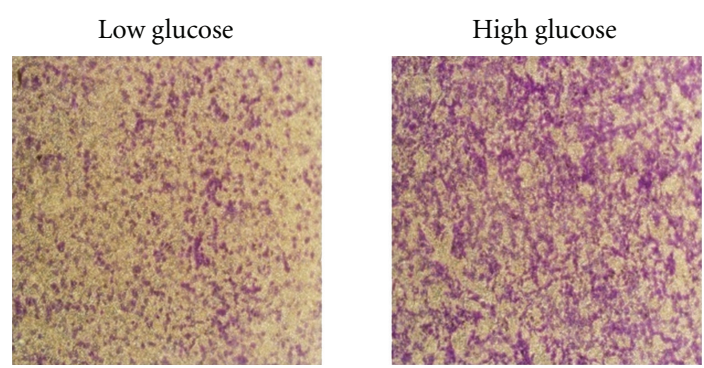

(b)

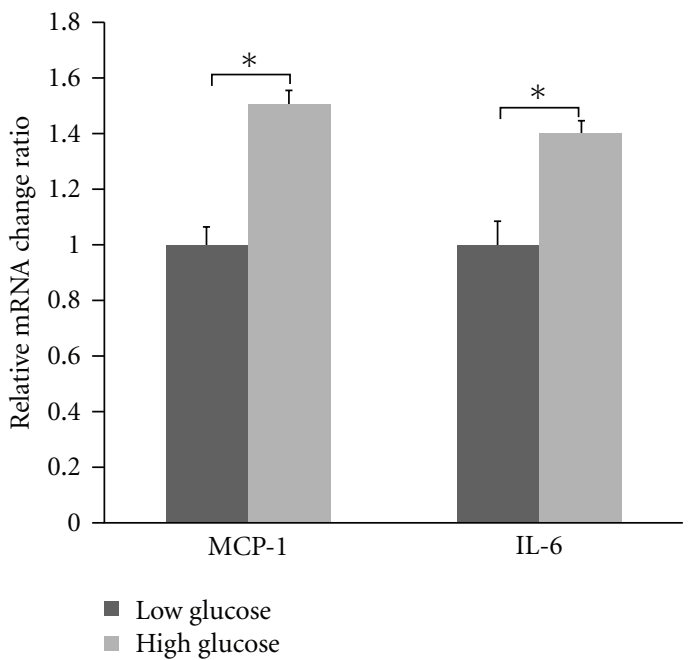

(c)

Figure 1: High glucose stimulated the proliferation, migration, and inflammatory gene expression of VSMCs. VSMCs cultured in lowglucose $(5.5 \mathrm{mmol} / \mathrm{L})$ or high-glucose $(25 \mathrm{mmol} / \mathrm{L})$ complete media were deprived of serum for $24 \mathrm{~h}$. In proliferation and inflammatory gene expression assays, VSMCs were stimulated by complete media for $6 \mathrm{~h}$, respectively. In migration assays, VSMCs were suspended, and then low-glucose or high-glucose complete media were added to the lower compartment respectively. (a) proliferation of VSMCs, (b) migration of VSMCs, and (c) inflammatory gene expression of VSMCs $\left({ }^{*} P<0.05\right)$.

air, 5\% $\left.\mathrm{CO}_{2}\right) .6 \mathrm{~h}$ later, nonmigrated cells were removed with a cotton swab, and the migrated cells were fixed with paraformaldehyde for $30 \mathrm{~min}$ and stained with crystal violet.

\subsection{Proliferation and Phagocytosis Assays by Flow Cytometry.} Click-iT EdU Flow Cytometry Assay Kits (invitrogen, cat. no. A10202) was used to detect VSMCs proliferation. Cells seeded in 6-well plates $\left(1.5 \times 10^{5}\right.$ cells/well $)$ were cultured up to subconfluence, and the medium was replaced by fresh serum-free medium. The cells were then treated with adenovirus infection for $48 \mathrm{~h}$. Following this, lowglucose $(5.5 \mathrm{mmol} / \mathrm{L})$ or high-glucose $(25 \mathrm{mmol} / \mathrm{L})$ DMEM supplemented with $10 \%$ FCS and $10 \mu \mathrm{M}$ EdU were added. After $6 \mathrm{~h}$, cells were suspended at $1 \times 10^{7}$ cells $/ \mathrm{mL}$ in $1 \%$ BSA in PBS. $100 \mu \mathrm{L}$ of cell suspension and $100 \mu \mathrm{L}$ Click-iT fixative were added to flow tubes, incubated for 15 minutes at room temperature, and protected from light. Cells were washed once with $3 \mathrm{~mL} 1 \%$ BSA in PBS. $100 \mu \mathrm{L}$ of the $1 \mathrm{X}$ saponin-based permeabilization and wash buffer was added, incubated for the 20 minutes at $4^{\circ} \mathrm{C}$ temperature, and protected from light. Each tube was washed. $0.5 \mathrm{~mL}$
Click-iT reaction cocktail were added, mixed well, incubated for 30 minutes at room temperature, and protected from light. Cells were washed once. $0.5 \mathrm{~mL} \mathrm{1X}$ saponin-based permeabilization and wash reagent was added. For the detection of EdU, 633/635 nm excitation with red emission filter (i.e., $660 / 20 \mathrm{~nm}$ or similar) was used.

Phagocytotic activity was revealed by microspheres. After $24 \mathrm{~h}$ serum deprivation, VSMCs were infected by Ad-PGC$1 \alpha$ or Ad-GFP for 48 hours. Then VSMCs were incubated with $1 \mu \mathrm{m}$ carboxylate-modified microspheres with red fluorescent $\left(2.7 \times 10^{6}\right.$ beads per $\left.\mathrm{mL}\right)$ for $10 \mathrm{~h}$. Cells with the above treatments were suspended with $0.05 \%$ trypsin and $0.02 \%$ EDTA and then washed three times in PBS. Following this, the cells were analyzed using excitation/emission maxima of 580/605 on FACSCalibur (Becton-Dickinson, San Jose, CA, USA).

2.8. Statistical Analysis. Data are expressed as means \pm SEM. Data were analyzed using a one-way ANOVA followed by Fisher's LSD post hoc test. Calculations were performed using SPSS/Windows version $12.5 \mathrm{~S}$ statistical package (SPSS, 

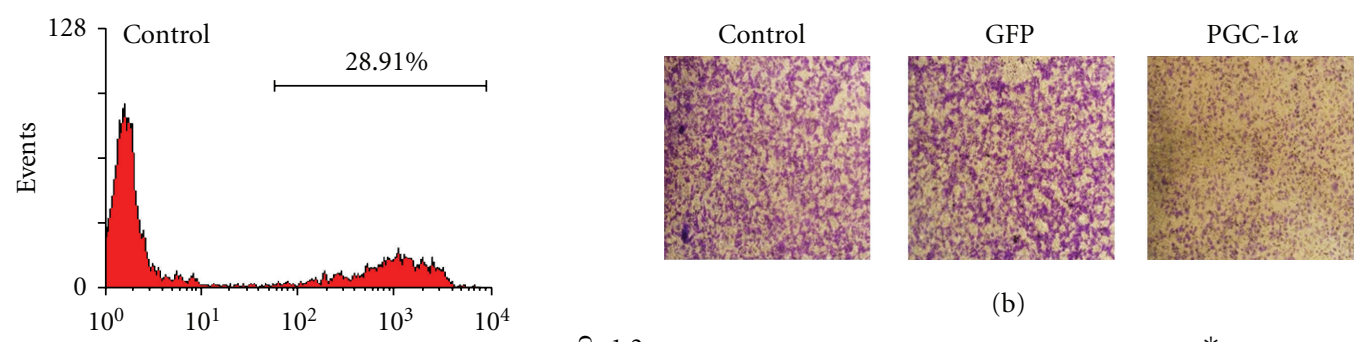

(b)

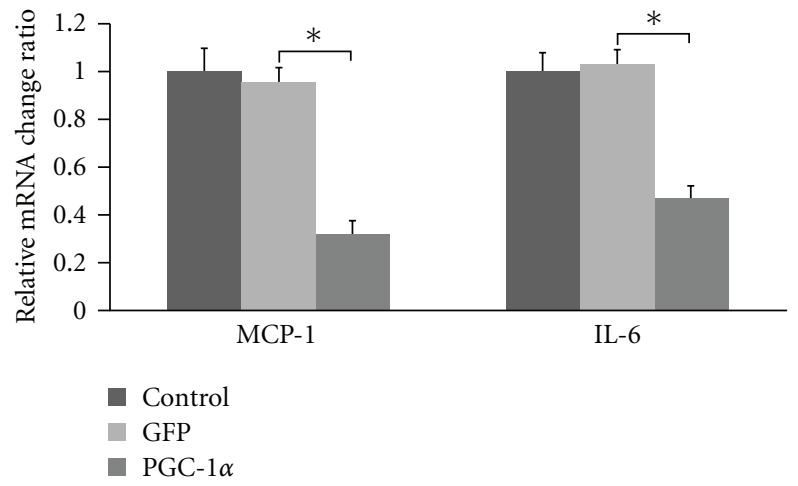

(c)

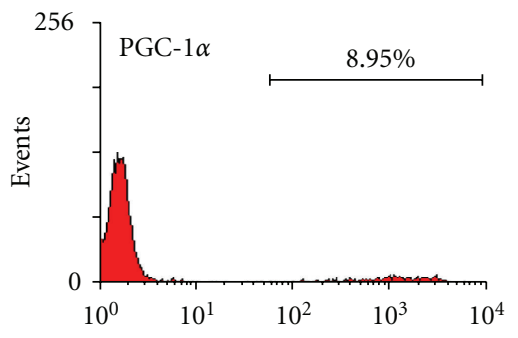

(a)

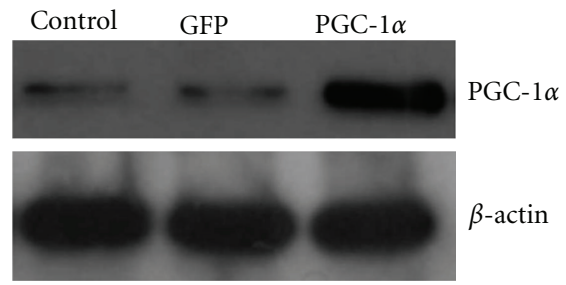

(d)

FIGURe 2: Overexpression of PGC- $1 \alpha$ inhibited proliferation, migration, and inflammatory gene expression of VSMCs in high glucose. VSMCs cultured in high-glucose $(25 \mathrm{mmol} / \mathrm{L})$ complete media were deprived of serum for $24 \mathrm{~h}$. The cells were then treated with adenovirus infection for $48 \mathrm{~h}$. (a) Proliferation of VSMCs, (b) migration of VSMCs, (c) inflammatory gene expression of VSMCs $(* P<0.05)$, and (d) Western blotting analysis for PGC- $1 \alpha$ in VSMCs.

Chicago, IL, USA). In all cases, $P<0.05$ was taken as statistically significant.

\section{Results}

3.1. High Glucose Stimulated the Proliferation, Migration, and Inflammatory Gene Expression of VSMCs. VSMCs cultured in low-glucose $(5.5 \mathrm{mmol} / \mathrm{L})$ or high-glucose $(25 \mathrm{mmol} / \mathrm{L})$ complete media were deprived of serum for $24 \mathrm{~h}$. In proliferation and inflammatory gene expression assays, VSMCs were stimulated by complete media for $6 \mathrm{~h}$, respectively, (Figures $1(\mathrm{a})$ and $1(\mathrm{c}))$. In migration assays, VSMCs were suspended, and then low-glucose or high-glucose complete media were added to the lower compartment, respectively, (Figure 1(b)). Results showed that the VSMCs in high glucose were in a preactivated state.

\subsection{Overexpression of PGC-1 $\alpha$ Inhibited Proliferation, Migra-} tion, and Inflammatory Gene Expression of VSMCs Induced by High Glucose. VSMCs cultured in high glucose $(25 \mathrm{mmol} / \mathrm{L})$ complete media were deprived of serum for $24 \mathrm{~h}$. The cells were then treated with adenovirus infection for $48 \mathrm{~h}$. In proliferation and inflammatory gene expression assays, VSMCs were incubated by complete media for $6 \mathrm{~h}$ (Figures $2(\mathrm{a})$ and 2(c)). In migration assays, VSMCs were suspended and then high-glucose complete media was added to the lower compartment (Figure 2(b)). Results showed that proliferation, migration, and inflammatory gene expression of VSMCs were inhibited. Expression of PGC- $1 \alpha$ in VSMCs treated with adenovirus infection was showed in Figure 2(d).

3.3. Overexpression of PGC-1 $\alpha$ Downregulated the VSMCsSpecific Genes Expression and Upregulated the MacrophageSpecific Genes Expression. To characterize the phenotypic changes after overexpression of PGC- $1 \alpha$, we determined the abundance of mRNA for several VSMCs [17] and macrophage-specific genes at the end of the adenovirus treatment for $48 \mathrm{~h}$. As shown in Figure 3(a), VSMCs infected by Ad-PGC- $1 \alpha$ had dramatically decreased in mRNA levels of $\alpha$-actin (57.7\% of control, $P<0.05)$, SM22 $\alpha$ (59.5\%, $P<0.05)$, smooth muscle myosin heavy chain $(31.5 \%, P<$ $0.05)$, and calponin H1 $(57.8 \%, P<0.05)$. At the same time, 


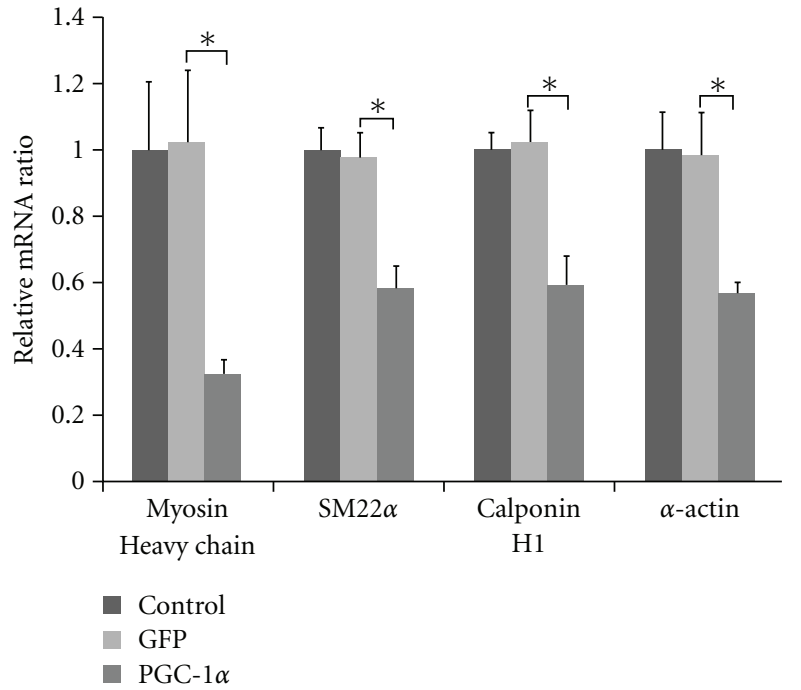

(a)

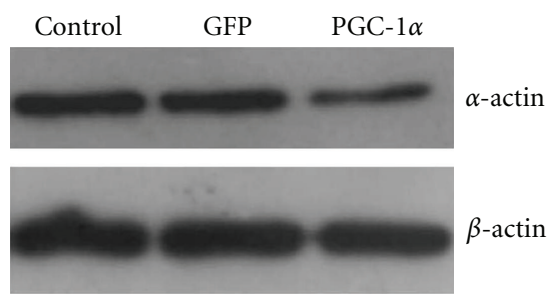

(c)

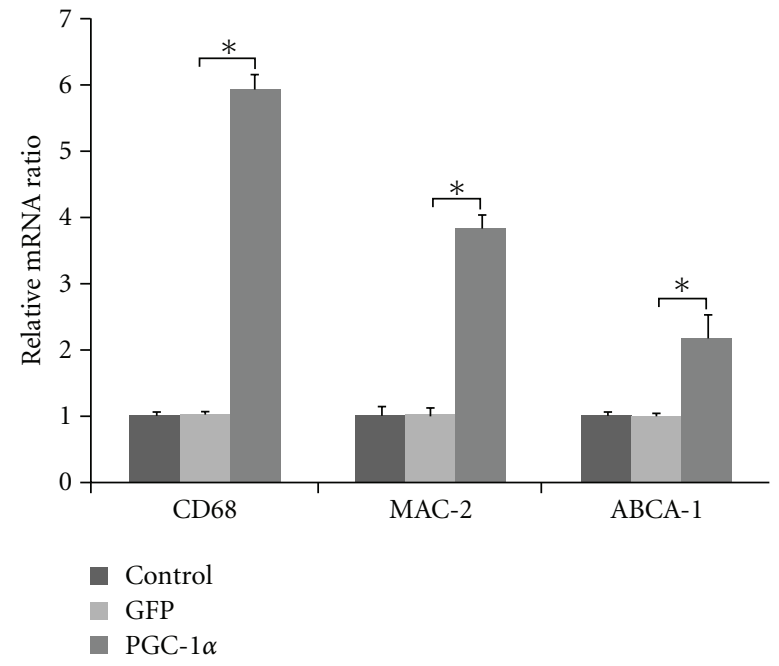

(b)

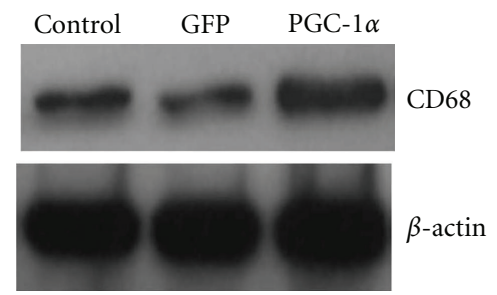

(d)

FIGURE 3: Overexpression of PGC-1 $\alpha$ downregulated VSMCs-specific genes and upregulated macrophage-specific genes. (a) Downregulation of VSMCs-specific genes ( $\left.{ }^{*} P<0.05\right)$, (b) upregulation of macrophage-specific genes $\left({ }^{*} P<0.05\right)$, (c) Western blotting analysis for $\alpha$-actin in VSMCs, and (d) Western blotting analysis for CD68 in VSMCs.

the mRNA levels of the macrophage-related proteins (CD68) increased (569\% of control, $P<0.05)$. Another macrophage marker, Mac-2, increased to $373 \%$ of controls $(P<0.05)$ (Figure 3(b)). ABCA-1, a key regulator of cholesterol efflux from peripheral cells to high-density lipoprotein [18] and associated predominantly with macrophages in vivo [19], increased to $221 \%(P<0.05)$ in VSMCs infected by AdPGC-1 $\alpha$ (Figure 3(b)).

Western blot also revealed the presence of specific proteins commonly taken as characteristic for VSMC or macrophage phenotype. Results are showed in Figures 3(c) and $3(\mathrm{~d})$.

3.4. Phagocytosis of VSMCs. To investigate whether VSMCs infected by Ad-PGC- $1 \alpha$ acquired functional aspects of macrophages, VSMCs were incubated in $1 \mu \mathrm{m}$ microspheres with red fluorescent and then assessed by flow cytometry.

As shown in Figure $4,27.36 \%$ of VSMCs infected by Ad-GFP had phagocytotic activity. However, the proportion of VSMCs having phagocytotic activity increased to $77.45 \%$ after overexpression of PGC- $1 \alpha$. This finding indicated that the acquisition of functional properties of macrophages existed in VSMCs, in addition to the increases of macrophage-specific gene and protein expression in VSMCs.

\section{Discussion}

Recent studies showed that VSMCs cultured under highglucose conditions mimic the diabetic pathophysiological state, which stimulates VSMCs proliferation, migration, and inflammatory genes expression $[6,20]$. High glucose stimulates reactive oxygen species production in cultured vascular smooth muscle cells [21]. ROSs have been implicated in all of these above responses including proliferation [22], migration [23], and inflammatory gene expression of VSMCs [24, 25]. PGC- $1 \alpha$ is a major transcriptional regulator of the mitochondrial detoxification system [26-29].

In the current study, we found that high-glucose stimulated VSMCs proliferation, migration, and expression of MCP- 1 and IL-6. Overexpression of PGC- $1 \alpha$ by adenoviruses infection blocked glucose-induced VSMCs proliferation, migration, and expression of MCP-1 and IL- 6 . These implied that overexpression of PGC- $1 \alpha$ could inhibit the preatherogenic responses in VSMCs, which were key features in the pathology of atherosclerosis.

VSMCs maintain considerable plasticity throughout life and can exhibit a diverse range of different phenotypes in response to changes in local environmental cues [17]. In vascular neointimal lesions, VSMCs display diminished expression of a number of proteins that are characteristics 


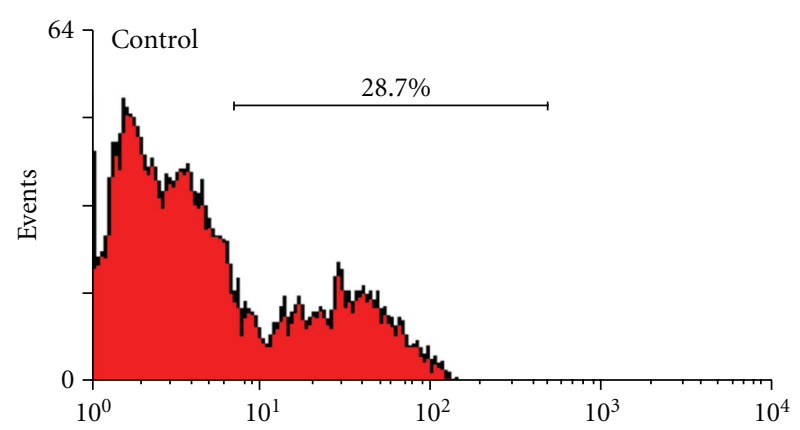

(a)

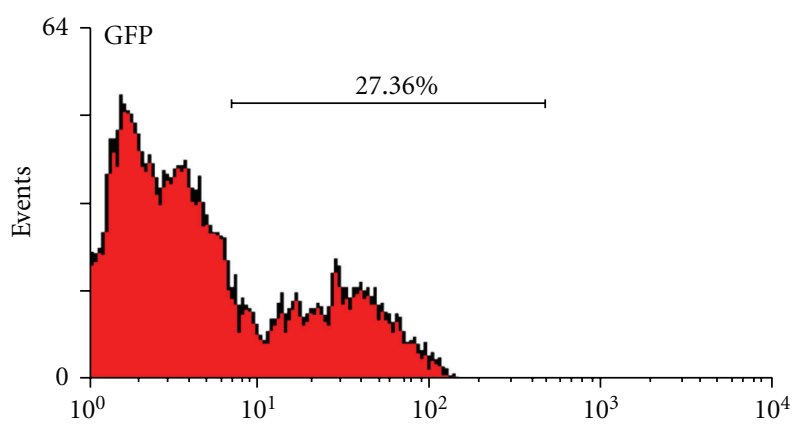

(b)

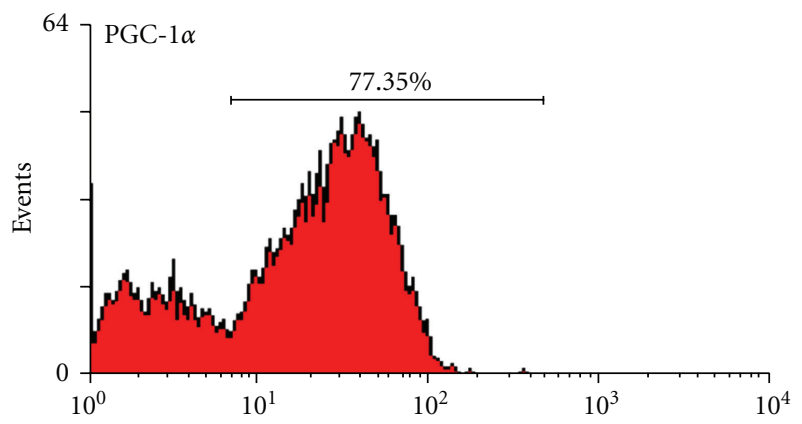

(c)

FIgure 4: Phagocytosis of VSMCs. VSMCs deprived of serum for $24 \mathrm{~h}$ were infected by Ad-PGC- $1 \alpha$ or Ad-GFP. After $48 \mathrm{~h}$, VSMCs were incubated with $1 \mu \mathrm{m}$ microspheres $\left(2.7 \times 10^{6}\right.$ beads per $\left.\mathrm{mL}\right)$ for $10 \mathrm{~h} .27 .36 \%$ of VSMCs infected by Ad-GFP had phagocytotic activity. However, the proportion of VSMCs having phagocytotic activity increased to $77.45 \%$ after overexpression of PGC- $1 \alpha$.

of fully differentiated VSMCs [30]. It is well established that the dedifferentiated VSMCs exhibit a number of properties, including enhanced migration, proliferation, and inflammatory gene expression [31].

Given the fact that overexpression of PGC- $1 \alpha$ suppressed the main preatherogenic responses in VSMCs, we examined the expression of VSMCs-related genes. All four smooth muscle markers assessed in the present study are related to the contraction function of VSMCs. Myosin heavy chain and $\alpha$-actin are essential components of smooth muscle contractile machinery [17]. Surprisingly, our results showed that overexpression of PGC- $1 \alpha$ rapidly decreased the genes expression of commonly accepted markers of the phenotype of VSMCs. The results were interpreted as evidences for a dedifferentiation process of VSMCs.

In further experiments, we found that the expression of macrophage-related genes was induced in VSMCs by overexpression of PGC- $1 \alpha$, and VSMCs acquired the macrophage-like functions assessed by phagocytotic activity. In light of the present results for macrophage-related genes expression of VSMCs, rather than dedifferentiating process, overexpression of PGC- $1 \alpha$ in VSMCs may be more appropriately considered as part of a transdifferentiation program that made VSMCs assume macrophage-like states. VSMCsderived foam cells are usually assumed to occur relatively late in the development of organized atherosclerotic plaque lesion. They retain sufficient phenotypic features to be identifiable by electron microscopy [3]. It has been reported that downregulation of VSMCs-related genes and Up-regulation of macrophage-related genes occurred in VSMCs-derived foam cells [4].

The transdifferentiation was good or bad? Firstly, overexpression of PGC- $1 \alpha$ inhibits the expression of MCP1 and makes it difficult to attract monocytes to bind to VSMCs. Then foam cells derived from macrophages would decrease. Secondly, VSMCs that were transdifferentiated to macrophage-like state compensated for the decrease of macrophage. Thirdly, VSMCs have the relative resistance to cholesterol loading-induced toxicity compared with macrophages, consistent with VSMCs being a more prominent histological feature of the advanced atherosclerotic lesions [32], which reduced the death of VSMCs and then favoured plaque stability.

The mechanisms that overexpression of PGC- $1 \alpha$ leads to the conversion of VSMCs to macrophage-like cells remain unknown. Recent studies demonstrated that two transcription factors: Liver X receptor $\alpha(\mathrm{LXR} \alpha)$ and PPAR $\gamma$ are strongly regulated by $\mathrm{PGC}-1 \alpha$. $\mathrm{LXR} \alpha$ is involved in the transcriptional control of a number of genes regulating the transport and catabolism of cholesterol [33]. Identified target genes of LXR $\alpha$ include the ATP-binding cassette transporter A1 (ABCA-1) [34], which is involved in reverse cholesterol transport. In our study, the expression of ABCA1 is increased by overexpression of PGC- $1 \alpha$ in VSMCs. Previous studies have indicated that $\operatorname{PPAR} \gamma$ regulates gain of macrophage-like phenotype in primary smooth muscle culture [35] and showed that the uptake of oxidized LDL by macrophages or of cholesterol in endothelial cells could 
lead to PPAR $\gamma$ activation [36, 37]. Future experiments will be needed to identify the pathways that are responsible for the transdifferentiation to macrophage-like state in VSMCs.

In summary, we demonstrated that PGC- $1 \alpha$ inhibited glucose-induced proliferation, migration, and inflammatory gene expression in VSMCs. In addition, overexpression of PGC- $1 \alpha$ decreased VSMCs-related genes expression, while it induced macrophage-related genes expression and phagocytosis in VSMCs. PGC- $1 \alpha$ transdifferentiated VSMCs to macrophage-like state. Such transdifferentiation increased the portion of VSMCs-derived foam cells in the plaque and then favored plaque stability. PGC- $1 \alpha$ may be a potential target for drug development of atherosclerosis.

\section{Sources of Funding}

This work was supported by Grants from the National Natural Science Foundation of China to Y. Xiang (nos. 30570731, 30871195, and 81070653).

\section{Acknowledgment}

The authors would like to thank Dr. Kelly (Center for Cardiovascular Research, Washington University School of Medicine) for his generous gifts of adenoviral plasmids.

\section{References}

[1] S. M. Schwartz, D. deBlois, and E. R. O'Brien, "The intima. Soil for atherosclerosis and restenosis," Circulation Research, vol. 77, no. 3, pp. 445-465, 1995.

[2] M. Klouche, S. Rose-John, W. Schmiedt, and S. Bhakdi, "Enzymatically degraded, nonoxidized LDL induces human vascular smooth muscle cell activation, foam cell transformation, and proliferation," Circulation, vol. 101, no. 15, pp. 1799-1805, 2000.

[3] A. Faggiotto, R. Ross, and L. Harker, "Studies of hypercholesterolemia in the nonhuman primate. I. Changes that lead to fatty streak formation," Arteriosclerosis, vol. 4, no. 4, pp. 323340, 1984.

[4] J. X. Rong, M. Shapiro, E. Trogan, and E. A. Fisher, "Transdifferentiation of mouse aortic smooth muscle cells to a macrophage-like state after cholesterol loading," Proceedings of the National Academy of Sciences of the United States of America, vol. 100, no. 23, pp. 13531-13536, 2003.

[5] M. Brownlee, "Biochemistry and molecular cell biology of diabetic complications," Nature, vol. 414, no. 6865, pp. 813820, 2001.

[6] K. K. Yerneni, W. Bai, B. V. Khan, R. M. Medford, and R. Natarajan, "Hyperglycemia-induced activation of nuclear transcription factor $\kappa \mathrm{B}$ in vascular smooth muscle cells," Diabetes, vol. 48, no. 4, pp. 855-864, 1999.

[7] P. Puigserver, Z. Wu, C. W. Park, R. Graves, M. Wright, and B. M. Spiegelman, "A cold-inducible coactivator of nuclear receptors linked to adaptive thermogenesis," Cell, vol. 92, no. 6, pp. 829-839, 1998.

[8] J. D. Lin, R. J. Yang, P. T. Tarr et al., "Hyperlipidemic effects of dietary saturated fats mediated through PGC- $1 \beta$ coactivation of SREBP," Cell, vol. 120, no. 2, pp. 261-273, 2005.

[9] Y. Kawakami, M. Tsuda, S. Takahashi et al., "Transcriptional coactivator $\mathrm{PGC}-1 \alpha$ regulates chondrogenesis via association with Sox9," Proceedings of the National Academy of Sciences of the United States of America, vol. 102, no. 7, pp. 2414-2419, 2005.

[10] J. C. Yoon, P. Puigserver, G. X. Chen et al., "Control of hepatic gluconeogenesis through the transcriptional coaotivator PGC1," Nature, vol. 413, no. 6852, pp. 131-138, 2001.

[11] J. C. Yoon, G. Xu, J. T. Deeney et al., "Suppression of $\beta$ cell energy metabolism and insulin release by PGC- $1 \alpha$," Developmental Cell, vol. 5, no. 1, pp. 73-83, 2003.

[12] Y. Zhang, C. Liu, L. Zhu et al., "PGC- $1 \alpha$ inhibits oleic acid induced proliferation and migration of rat vascular smooth muscle cells," PLoS ONE, vol. 2, no. 11, Article ID e1137, 2007.

[13] D. Gordon, L. G. Mohai, and S. M. Schwartz, "Induction of polyploidy in cultures of neonatal rat aortic smooth muscle cells," Circulation Research, vol. 59, no. 6, pp. 633-644, 1986.

[14] S. Miyake, M. Makimura, Y. Kanegae et al., "Efficient generation of recombinant adenoviruses using adenovirus DNAterminal protein complex and a cosmid bearing the full-length virus genome," Proceedings of the National Academy of Sciences of the United States of America, vol. 93, no. 3, pp. 1320-1324, 1996.

[15] K. J. Livak and T. D. Schmittgen, "Analysis of relative gene expression data using real-time quantitative PCR and the 2$\Delta \Delta$ CT method," Methods, vol. 25, no. 4, pp. 402-408, 2001.

[16] G. R. Grotendorst, H. E. Seppa, H. K. Kleinman, and G. R. Martin, "Attachment of smooth muscle cells to collagen and their migration toward platelet-derived growth factor," Proceedings of the National Academy of Sciences of the United States of America, vol. 78, no. 6 I, pp. 3669-3672, 1981.

[17] G. K. Owens, "Regulation of differentiation of vascular smooth muscle cells," Physiological Reviews, vol. 75, no. 3, pp. 487-517, 1995.

[18] S. G. Young and C. J. Fielding, "The ABCs of cholesterol efflux," Nature Genetics, vol. 22, no. 4, pp. 316-318, 1999.

[19] S. B. Joseph, E. McKilligin, L. Pei et al., "Synthetic LXR ligand inhibits the development of atherosclerosis in mice," Proceedings of the National Academy of Sciences of the United States of America, vol. 99, no. 11, pp. 7604-7609, 2002.

[20] K. Yasunari, M. Kano, H. Kano, K. Yokokawa, M. Minami, and J. Yoshikawa, "Mechanisms of action of troglitazone in the prevention of high glucose- induced migration and proliferation of cultured coronary smooth muscle cells," Circulation Research, vol. 81, no. 6, pp. 953-962, 1997.

[21] T. Inoguchi, P. Li, F. Umeda et al., "High glucose level and free fatty acid stimulate reactive oxygen species production through protein kinase C-dependent activation of $\mathrm{NAD}(\mathrm{P}) \mathrm{H}$ oxidase in cultured vascular cells," Diabetes, vol. 49, no. 11, pp. 1939-1945, 2000.

[22] M. Sundaresan, Z. X. Yu, V. J. Ferrans, K. Irani, and T. Finkel, "Requirement for generation of $\mathrm{H}_{2} \mathrm{O}_{2}$ for platelet-derived growth factor signal transduction," Science, vol. 270, no. 5234, pp. 296-299, 1995.

[23] D. Weber, P. Seshiah, Y. Taniyama, and K. K. Griendling, "Src-dependent migration of vascular smooth muscle cells by PDGF is reactive oxygen species dependent," Circulation, vol. 106, pp. 260-260, 2002.

[24] X. L. Chen, P. E. Tummala, M. T. Olbrych, R. W. Alexander, and R. M. Medford, "Angiotensin II induces monocyte chemoattractant protein-1 gene expression in rat vascular smooth muscle cells," Circulation Research, vol. 83, no. 9, pp. 952-959, 1998.

[25] Y. Q. Han, M. S. Runge, and A. R. Brasier, "Angiotensin II induces interleukin-6 transcription in vascular smooth 
muscle cells through pleiotropic activation of nuclear factor$\kappa \mathrm{b}$ transcription factors," Circulation Research, vol. 84, no. 6, pp. 695-703, 1999.

[26] D. Kukidome, T. Nishikawa, K. Sonoda et al., "Activation of AMP-activated protein kinase reduces hyperglycemiainduced mitochondrial reactive oxygen species production and promotes mitochondrial biogenesis in human umbilical vein endothelial cells," Diabetes, vol. 55, no. 1, pp. 120-127, 2006.

[27] J. St-Pierre, J. Lin, S. Krauss et al., "Bioenergetic analysis of peroxisome proliferator-activated receptor $\gamma$ coactivators $1 \alpha$ and $1 \beta$ (PGC- $1 \alpha$ and PGC-1 $\beta$ ) in muscle cells," Journal of Biological Chemistry, vol. 278, no. 29, pp. 26597-26603, 2003.

[28] I. Valle, A. Alvarez-Barrientos, E. Arza, S. Lamas, and M. Monsalve, "PGC- $1 \alpha$ regulates the mitochondrial antioxidant defense system in vascular endothelial cells," Cardiovascular Research, vol. 66, no. 3, pp. 562-573, 2005.

[29] J. St-Pierre, S. Drori, M. Uldry et al., "Suppression of reactive oxygen species and neurodegeneration by the PGC-1 transcriptional coactivators," Cell, vol. 127, no. 2, pp. 397-408, 2006.

[30] C. P. Regan, P. J. Adam, C. S. Madsen, and G. K. Owens, "Molecular mechanisms of decreased smooth muscle differentiation marker expression after vascular injury," Journal of Clinical Investigation, vol. 106, no. 9, pp. 1139-1147, 2000.

[31] R. Ross, "The pathogenesis of atherosclerosis: a perspective for the 1990s," Nature, vol. 362, no. 6423, pp. 801-809, 1993.

[32] J. X. Rong, J. Kusunoki, P. Oelkers, S. L. Sturley, and E. A. Fisher, "Acyl-coenzymeA (CoA):cholesterol acyltransferase inhibition in rat and human aortic smooth muscle cells is nontoxic and retards foam cell formation," Arteriosclerosis, Thrombosis, and Vascular Biology, vol. 25, no. 1, pp. 122-127, 2005.

[33] B. M. Forman, B. F. Ruan, J. Chen, G. J. Schroepfer, and R. M. Evans, "The orphan nuclear receptor LXRa is positively and negatively regulated by distinct products of mevalonate metabolism," Proceedings of the National Academy of Sciences of the United States of America, vol. 94, no. 20, pp. 10588-10593, 1997.

[34] P. Costet, Y. Luo, N. Wang, and A. R. Tall, "Sterol-dependent transactivation of the $\mathrm{ABC} 1$ promoter by the liver $\mathrm{X}$ receptor/retinoid X receptor," Journal of Biological Chemistry, vol. 275, no. 36, pp. 28240-28245, 2000.

[35] K. Matsumoto, K. Hirano, S. Nozaki et al., "Expression of macrophage $(\mathrm{M} \varphi)$ scavenger receptor, CD36, in cultured human aortic smooth muscle cells in association with expression of peroxisome proliferator activated receptor- $\gamma$, which regulates gain of $\mathrm{M} \varphi$-like phenotype in vitro, and its implication in atherogenesis," Arteriosclerosis, Thrombosis, and Vascular Biology, vol. 20, no. 4, pp. 1027-1032, 2000.

[36] P. Tontonoz, L. Nagy, J. G. Alvarez, V. A. Thomazy, and R. M. Evans, "PPAR $\gamma$ promotes monocyte/macrophage differentiation and uptake of oxidized LDL," Cell, vol. 93, no. 2, pp. 241252, 1998.

[37] P. Meerarani, E. J. Smart, M. Toborek, G. A. Boissonneault, and B. Hennig, "Cholesterol attenuates linoleic acid-induced endothelial cell activation," Metabolism, vol. 52, no. 4, pp. 493 500, 2003 . 

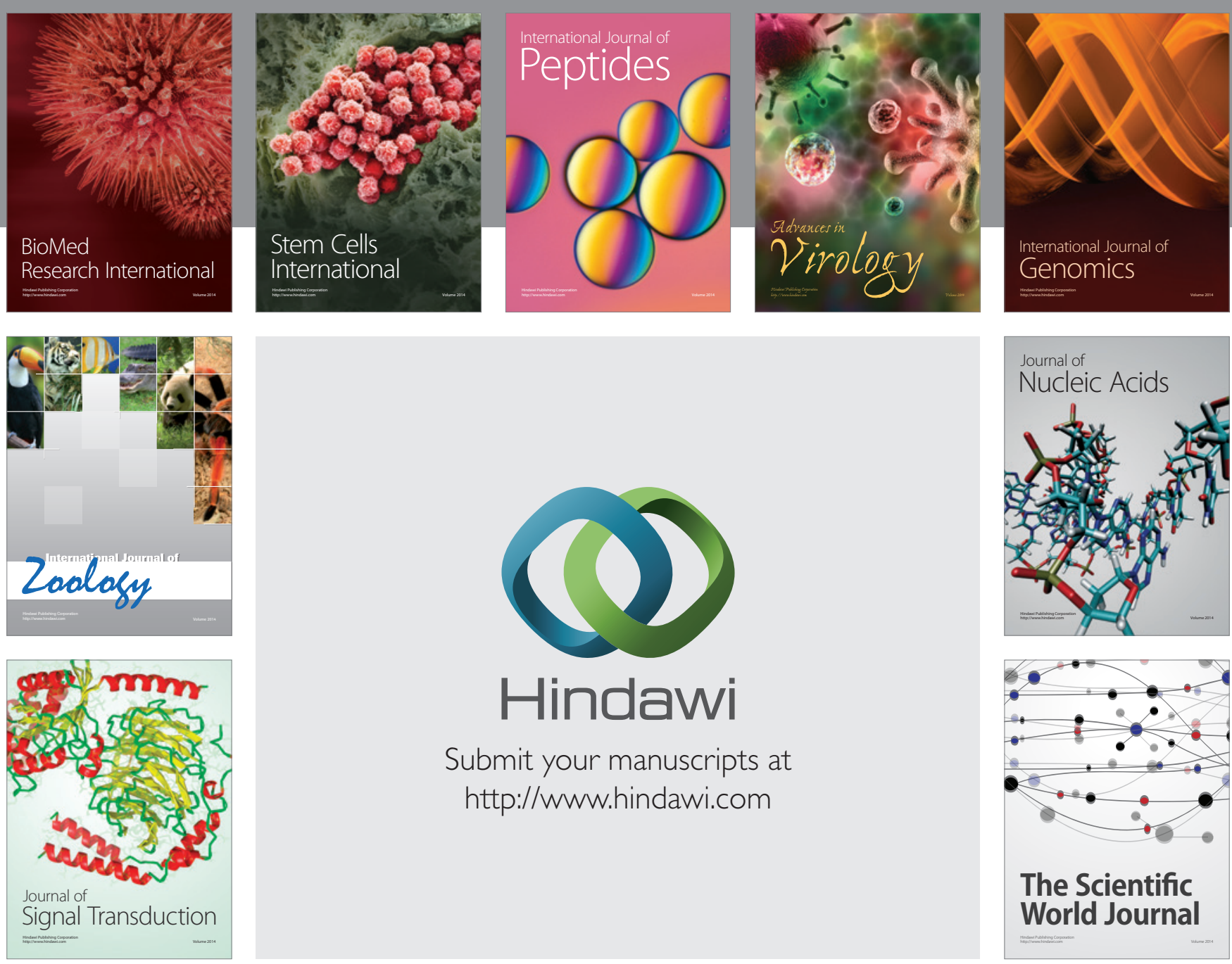

Submit your manuscripts at

http://www.hindawi.com
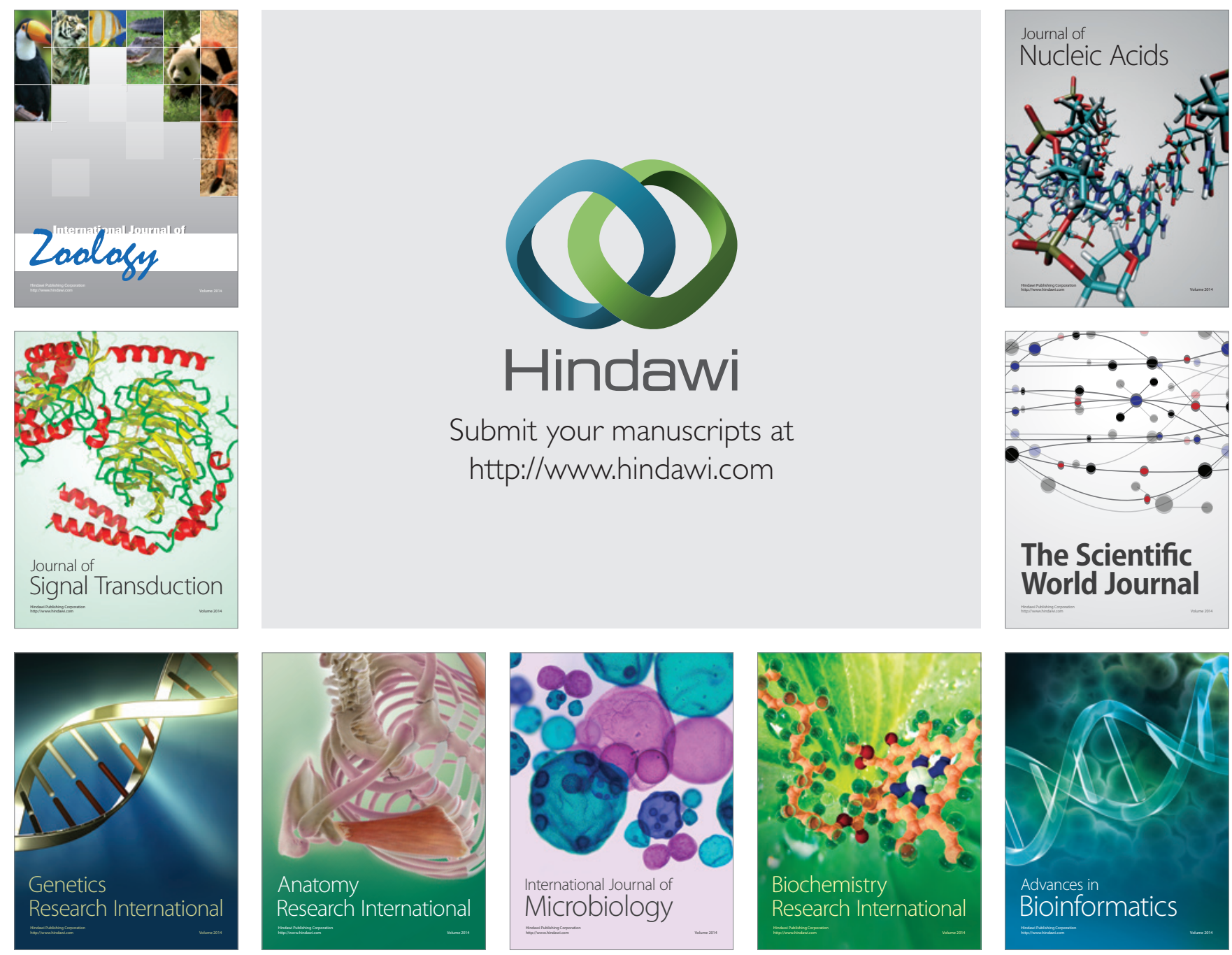

The Scientific World Journal
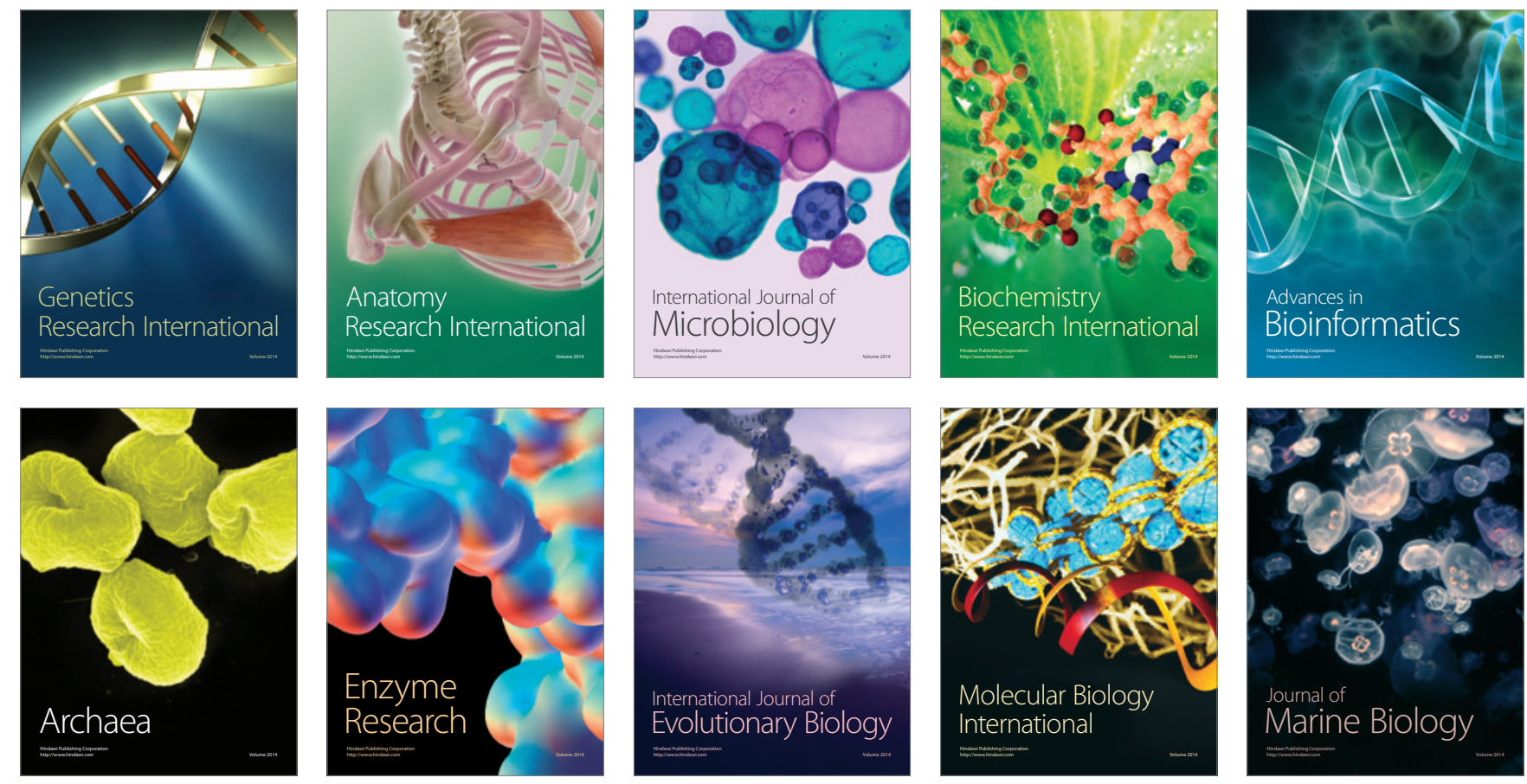